$\begin{array}{ll}\text { Volume } & : 7 \\ \text { Nomor } & : \mathbf{3} \\ \text { Bulan } & : \text { Agustus } \\ \text { Tahun } & : \mathbf{2 0 2 1}\end{array}$

\title{
Pengembangan Kecerdasan Naturalis Anak Usia Dini melalui Model Pendidikan Lingkungan Unesco
}

\author{
I Komang Wisnu Budi Wijaya \\ Putu Ayu Septiari Dewi \\ Universitas Hindu Negeri I Gusti Bagus Sugriwa Denpasar \\ Pos-el: wisnu.budiwijaya240191@gmail.com, ayuwindhu@gmail.com
}

DOI: $10.32884 /$ ideas.v7i3.449

\begin{abstract}
Abstrak
Penelitian ini bertujuan untuk mendeskripsikan strategi pengembangan kecerdasan naturalis anak usia dini melalui model pendidikan lingkungan UNESCO. Penelitian ini tergolong dalam penelitian studi literatur. Sumber data penelitian berasal dari buku, jurnal, makalah, dan karya ilmiah lainnya yang berkaitan dengan kecerdasan naturalis dan model pendidikan lingkungan UNESCO. Data yang terkumpul kemudian dianalisis dengan teknik analisis isi. Hasil penelitian menyatakan bahwa model pendidikan lingkungan UNESCO dapat digunakan untuk mengembangkan kecerdasan naturalis anak usia dini, yaitu melalui kegiatan membaca, menggunakan lingkungan sebagai sumber belajar, mengelola lingkungan dan budaya peduli lingkungan. Dalam pengembangan kecerdasan naturalis, peran guru dan orang tua adalah sebagai pengawas, motivator, dan fasilitator.
\end{abstract}

\section{Kata Kunci}

kecerdasan naturalis, anak usia dini, pendidikan lingkungan

\begin{abstract}
This study aims to describe strategies for developing naturalist intelligence for early childhood through the UNESCO Environmental Education Model. This research belongs to the literature research. Sources of research data are from books, journals, papers and other scientific works related to naturalist intelligence and the UNESCO Environmental Education Model. The collected data was analyzed using content analysis techniques. The results of the study state that the UNESCO Environmental Education Model can be used to develop naturalist intelligence for early childhood, namely through reading activities, using the environment as a learning resource, managing the environment and a culture of environmental care. In developing naturalist intelligence, the roles of teachers and parents are as supervisors, motivators and facilitators.
\end{abstract}

Keywords

naturalist intelligence, early childhood, environmental education

\section{Pendahuluan}

Konsep tentang kecerdasan kini telah dimaknai secara luas oleh masyarakat. Sebelumnya kecerdasan selalu identik dengan kemampuan logika matematis. Namun, oleh Gardner (1993) telah dicetuskan tentang konsep kecerdasan berganda (multiple intelligence). Kecerdasan majemuk terdiri dari 9 (sembilan) macam kecerdasan yaitu kecerdasan verbal, linguistik, logika matematis, spasial, musikal, kinestetik, interpersonal, intrapersonal, eksistensial dan naturalis (Rahmah, 2008).

Salah satu jenis kecerdasan yang termasuk dalam kecerdasan berganda adalah kecerdasan naturalis (Wijaya, 2018). Kecerdasan naturalis adalah kemampuan untuk mengenali, membedakan dan mengelo mpokkan segala hal yang berkaitan dengan alam baik itu flora fauna dan komponen abiotik sebagai komponen pendukung (Juniarti, 2015). Kecerdasan naturalis penting ditanamkan kepada setiap individu agar nantinya mereka tu mbuh menjadi insan yang memiliki karakter peduli lingkungan (Rocmah, 2016).

Kecerdasan naturalis hendaknya sudah mulai ditanamkan sejak anak berusia dini. Hal itu disebabkan pada usia itu anak sedang berada pada massa keemasan (golden age) sehingga perkembangan kecerdasan anak sedang berada pada taraf optimal. Selain itu pada usia tersebut anak memiliki naluri keingintahuan dan minat eksplorasi

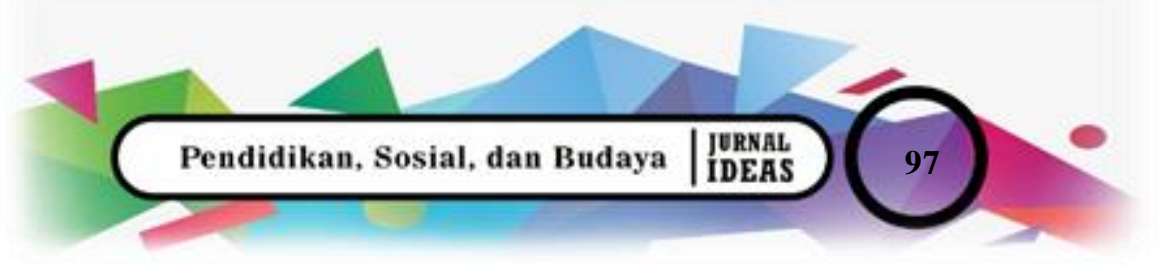


yang tinggi terhadap alam sekitarnya (I. K. W. B. Wijaya, 2019b). Dengan demikian, mengembangkan kecerdas an naturalis pada anak usia dini adalah sebuah hal yang tepat.

Pengembangan kecerdasan naturalis pada anak usia dini memerlukan sebuah model pendidikan. Salah satu model pendidikan yang disarankan adalah model pendidikan lingkungan UNESCO. Model pendidikan lingkungan UNESCO adalah sebuah model pendidikan yang bertujuan menanamkan wawasan lingkungan, karakter positif terhadap lingkungan serta strategi menjaga dan mengelola lingkungan agar terhindar dari kerusakan (Supadmini, Wijaya, \& Larashanti, 2020a). Konsep pendidikan lingkungan ini nampaknya cocok untuk mengembangkan kecerdasan naturalis karena dengan model ini anak belajar langsung pada lingkungan sekitarnya sehingga dapat mengenal dan memahami lingkungannya secara mendalam.

\section{Metode}

Penelitian ini termasuk dalam penelitian studi literatur yaitu penelitian yang menggunakan literatur sebagai sumber data utama kemudian dilakukan analisis (Wijaya, Darmayanti, \& Jayadiningrat, 2021). Peneliti mengumpulkan berbagai literatur yang berkaitan dengan kecerdasan naturalis dan pendidikan lingkungan. Literatur yang dikumpulkan berupa buku, jurnal, makalah dan karya ilmiah lainnya. Berkaitan denga sumber literatur jurnal syaratnya adalah jurnal selama sepuluh tahun terakhir dan terindeks Google Scholar. Setelah terkumpul kemudian dilakukan teknik analisis isi yaitu teknik analisis yang teknik analisis terhadap isi atau pesan dari sebuah sumber tertulis (Supadmini, Wijaya, \& Larashanti, 2020b).

\section{Hasil dan Pembahasan \\ Hasil \\ Model Pendidikan Lingkungan UNESCO}

Pendidikan lingkungan pada dasarnya adalah sebuah upaya yang dilakukan secara sadar dan sistematis untuk membentuk individu yang memiliki pengetahuan, keterampilan dan sikap yang baik mengenai lingkungan (Setyowati, Sunarko, Rudatin, \& Sedyawati, 2014). Menurut konferensi Tbilisi tahun 1977 tujuan dari pendidikan lingkungan hidup adalah sebagaiberikut.

1. Menjelaskan berbagai permasalahan tentang saling keterkaitan antara ekonomi, politik dengan kondisi ekologi di lingkungan kota dan pedesaan.

2. Memberikan kesempatan kepada setiap orang untuk mengembangkan pengetahuan, nilai, sikap, dan komitmen untuk memperbaiki lingkungan.

3. Menciptakan pola perilaku masyarakat yang positif terhadap kelestarian lingkungan (Muhaimin, 2015).

Dalam melaksanakan pendidikan lingkungan hendaknya memerhatikan beberapa hal, yaitu: (1) pendekatan pembelajaran yang berorientasi lokal dan global; (2) fokus pada perspektif lingkungan yang komprehensif; (3) mengembangkan perilaku bertanggung jawab terhadap lingkungan; (4) pendekatan interdisipliner dalam memahami permasalahan lingkungan; dan (5) pembelajaran dengan cara kooperatif (Hayati, 2008), kemudian unsur-unsur yang hendaknya ada dalam proses pendidikan lingkungan adalah sebagai berikut.

1. Unsur empiris, yaitu memberikan kesempatan kepada siswa untuk berinteraksi langsung dengan lingkungannya.

2. Unsur kepedulian, yaitu mampu membangkitkan kesadaran anak tentang lingkungannya.

3. Unsur estetik, yaitu mampu memberikan pengaruh kepada anak bahwa lingkungan yang baik akan menghadirkan nuansa keindahan (estetik).

4. Unsur sosial, yaitu berkaitan dengan keterkaitan lingkungan dengan kehidupan sosial, ekonomi ,dan budaya masyarakat (Muhaimin, 2015).

Salah satu lembaga PBB yaitu UNESCO telah mengembangkan model pendidikan lingkungan. Model pendidikan lingkungan yang dikembangkan terdiri dari tiga hal yaitu pendidikan tentang lingkungan (education about environment), pendidikan di dalam lingkungan (education in environment) dan pendidikan untuk lingkungan (education for environment). Pendidikan tentang lingkungan bertujuan untuk mengembangkan as pek kognitif; pendidikan untuk lingkungan memiliki tujuan menanamkan aspek afektif, sedangkan pendidikan di lingkungan menanamkan aspek psikomotor anak (Prasetyo \& Hariyanto, 2017).

\section{Kecerdasan Naturalis}




$\begin{array}{ll}\text { Volume } & : 7 \\ \text { Nomor } & : 3 \\ \text { Bulan } & : \text { Agustus } \\ \text { Tahun } & : 2021\end{array}$

Kecerdasan naturalis merupakan uku ran seberapa tinggi kepekaan seseorang terhadap lingkungan alam baik itu tumbuhan, binatang yang memerlukan klasifikasi dan hierarki (Yusuf, 2019). Anak yang memiliki kecerdasan naturalis tinggi umumnya memiliki perhatian yang tinggi terhadap hewan, tumbuhan beserta komponen abiotiknya. Komponen kecerdasan naturalis mencakup aspek kognitif, psikomotor dan afektif. Untuk aspek kognitif dan psikomotor terdiri atas:

1. pemahaman tentang hewan;

2. mengklasifikasi hewan;

3. memahami tentang tumbuhan;

4. mengklasifikasi tumbuhan;

5. memahami gejala alam;

6. mengelola sumber daya alam;

7. memahami permasalahan lingkungan (Yusuf, 2019).

Kemudian untuk komponen afektif dicetuskan oleh de Roos (2014) yang menyatakan bahwa anak yang memiliki kecerdasan naturalis akan memiliki sikap sebagaiberikut.

1. Merasa senang bila berada di luar rumah.

2. Berjuang untuk keseimbangan alam, pikiran dan tubuh.

3. Menunjukkan empati dengan alam dan lingkungan hidup.

4. Memiliki rasa tanggung jawab kuat terhadap lingkungan.

5. Memiliki kepekaan terhadap kerusakan lingkungan dan ancaman kepunahan flora dan fauna.

6. Menikmati pengalaman eksplorasi dan petualangan terbuka.

7. Merasa memiliki keterkaitan dengan kehidupan hewan dan tumbuhan (Yusuf, 2019).

\section{Pembahasan}

\section{Pengembangan Kecerdasan Naturalis melalui Pendidikan Lingkungan versi UNESCO}

Pengembangan kecerdasan naturalis dapat dilaku kan pada anak usia dini mengingat pada usia ini kecerdasannya sedang mengalami pertumbuhan yang optimal (Wijaya, 2019a). Pengembangan kecerdasan naturalis dapat dilakukan melalui model pendidikan lingkungan UNESCO dengan memerhatikan perkembangan kognitif, afektif dan psikomotor peserta didik. Strategi pengembangan kecerdasan naturalis melalui pendidikan lingkungan UNESCO disajikan dalam tabel 1.

Tabel 1

Pengembangan Kecerdasan Naturalis Melalui Model Pendidikan Lingkungan UNESCO

\begin{tabular}{|c|c|c|c|}
\hline No. & Komponen & Kegiatan Pembelajaran & $\begin{array}{l}\text { Kecerdasan Naturalis } \\
\text { yang Dikembangkan }\end{array}$ \\
\hline 1 & $\begin{array}{l}\text { Pendidikan tentang } \\
\text { lingkungan }\end{array}$ & $\begin{array}{l}\text { a. Memperkenalkan kepada anak berbagai } \\
\text { macam tanaman dan hewan melalui media } \\
\text { pembelajaran yang menarik baik itu } \\
\text { poster, video, dan media pembelajaran } \\
\text { lainnya. } \\
\text { b. Menyediakan fasilitas berupa buku bacaan } \\
\text { tentang flora dan fauna kepada anak yang } \\
\text { disesuaikan dengan perkembangan anak. } \\
\text { c. Mengajak anak menonton berita tentang } \\
\text { kerusakan lingkungan sambil menjelaskan } \\
\text { penyebabnya dengan menggunakan bahasa } \\
\text { yang sederhana dan mudah dipahami. }\end{array}$ & $\begin{array}{ll}\text { a. } & \text { Pemahaman tentang hewan } \\
\text { b. Pemahaman tentang tumbuhan } \\
\text { c. Memahami gejala alam } \\
\text { d. Memahami tentang kerusakan ling- } \\
\text { kungan }\end{array}$ \\
\hline 2 & $\begin{array}{l}\text { Pendidikan } \\
\text { di lingkungan }\end{array}$ & $\begin{array}{l}\text { a. Mengajak anak bermain ke halaman } \\
\text { terbuka dan memperkenalkan berbagai } \\
\text { jenis tanaman dan hewan. } \\
\text { b. Melatih anak untuk mengklasifikasikan } \\
\text { tumbuhan dan hewan secara sederhana } \\
\text { misalnya mengelompokkan tumbuhan } \\
\text { yang berbunga atau berbuah, men gelom- } \\
\text { pokkan hewan yang berkaki empat, hewan } \\
\text { yang bisa terbang dan jenis lainnya. } \\
\text { c. Melatih anak cara merawat hewan dan } \\
\text { tanaman, misalnya membiasakan anak } \\
\text { agar rutin menyiram tanaman atau mem- }\end{array}$ & $\begin{array}{l}\text { a. Mengklasifikasi hewan } \\
\text { b. Mengklasifikasi tanaman } \\
\text { c. Mengelola sumber daya alam } \\
\text { d. Rasa senang bermain di luar rumah } \\
\text { e. Tanggung jawab terhadap lingku- } \\
\text { ngan } \\
\text { f. Menikmati eksplorasi di alam } \\
\text { terbuka }\end{array}$ \\
\hline
\end{tabular}




\begin{tabular}{|c|c|c|c|}
\hline & & $\begin{array}{l}\text { beri makan kepada hewan yang dipelihara. } \\
\text { d. Melatih anak memperbanyak tanaman } \\
\text { yang paling sederhana, misalny a dengan } \\
\text { teknik setek batang. }\end{array}$ & \\
\hline 3 & $\begin{array}{l}\text { Pendidikan untuk } \\
\text { Lingkungan }\end{array}$ & $\begin{array}{l}\text { a. Melatih anak untuk selalu membuang } \\
\text { sampah pada tempat dan jenisnya. } \\
\text { b. Melatih anak mengolah sampah dengan } \\
\text { kegiatan yang menyenangkan misalnya } \\
\text { membuat kerajinan tangan dari botol } \\
\text { plastik bekas. } \\
\text { c. Melibatkan anak dalam kegiatan } \\
\text { kebersihan lingkungan rumah dan } \\
\text { sekitarnya. }\end{array}$ & $\begin{array}{l}\text { a. Empati dengan alam dan lingku- } \\
\text { ngan hidup. } \\
\text { b. Rasa tanggung jawab kuat terhadap } \\
\text { lingkungan. } \\
\text { c. Kepekaan terhadap kerusakan ling- } \\
\text { kungan dan ancaman kepunahan } \\
\text { flora dan fauna. } \\
\text { d. Merasa memiliki keterkaitan } \\
\text { dengan kehidupan hewan dan tum- } \\
\text { buhan. }\end{array}$ \\
\hline
\end{tabular}

\section{Peran Orang Tua dan Guru dalam Pengembangan Kecerdasan Naturalis Anak Usia Dini}

Orang tua dan guru memiliki peranan penting dalam pengembangan kecerdasan naturalis anak usia dini. Orang tua merupakan pendidik pertama dan utama sedangkan guru lebih berperan dalam mengasah dan memperdalam hal-hal yang sudah didapat anak dalam pendidikan keluarga. Peran orang tua dan guru dalam pengembangan kecerdas an naturalis adalah sebagaiberikut.

1. Sebagai motivator. Guru dan orang tua hendaknya mampu memotivasi anak dalam mengembangkan kecerdasan naturalis (Wijaya, 2018). Motivasi merupakan sebuah dorongan yang sangat berarti bagi ana $\mathrm{k}$ usia dini ketika sedang belajar.

2. Sebagai fasilitator. Orang tua dan guru dapat memfasilitasi anak usia dini ketika mengembangkan kecerdasan naturalis yaitu berupa informasi, sarana belajar dan fasilitas lainnya.

3. Sebagai pengawas. Orang tua dan guru hendaknya selalu mengawasi perkembangan kecerdasan naturalis anak dan memfokuskan pada as pekyang belum berkembang (Uno, 2007).

\section{Simpulan}

Berdasarkan uraian pembahasan, dapat disimpulkan bahwa pengembangan kecerdasan naturalis anak usia dini dapat dikembangkan melalui model pendidikan lingkungan UNESCO. Pengembangan kecerdasan naturalis dapat dilakukan dengan memerhatikan perkembangan kognitif, psikomotor dan afektif anak. Dalam pengembangan kecerdasan naturalis, peran orang tua dan guru sangat besar yaitu sebagai motivator, fasilitator dan pengawas.

\section{Daftar Rujukan}

Hayati, S. (2008). Pendidikan Lingkungan Hidup dalam Membentuk Perilaku Lingkungan Bertanggung Jawab. Bandung.

Juniarti, Y. (2015). Peningkat an Kecerdasan Naturalis Melalui Metode Kunjungan Lapangan (Field Trip). Jumal Pendidikan Usia Dini, 9(2), $267-284$.

Muhaimin. (2015). Membangun Kecerdasan Ekologis. Bandung: Penerbit Alfabeta.

Prasetyo, K., \& Hariyanto. (2017). Pendidikan Lingkungan Indonesia, Dasar Pedagogi dan Metodologi. Bandung: PT. Remaja Rosdakarya. Rahmah, S. (2008). Teori Kecerdasan Majemuk Howard Gardner dan Pengembangannya Pada Metode Pembelajaran Pendidikan Agama Islam untuk Anak Usia Sekolah Dasar. Jurnal Pendidikan Agama Islam, V(1), 89-110.

Rocmah, L. I. (2016). Peningkatan Kecerdasan Naturalis Melalui Bermain Messy Play Terhadap Anak Usia 5 - 6 Tahun. Jurnal Pedagogia, $5(1), 47-56$

Setyowati, D. L., Sunarko, Rudatin, \& Sedyawati, S. M. R. (2014). Pendidikan Lingkungan Hidup. Semarang: Universitas Negeri Semarang. Supadmini, N. K., Wisnu Budi Wijaya, I. K., \& Larashanti, I. A. D. (2020). Implementasi Model Pendidikan Lingkungan UNESCO Di Sekolah Dasar. Cetta: Jurnallimu Pendidikan, 3(1), 77-83. https://doi.org/10.37329/cetta.v3i1.416

Uno, H. B. (2007). Profesi Kependidikan. Jakarta: Bumi Aksara.

Wijaya, I. K. W. B. (2018). Menanamkan Konsep Catur Paramita Pada Anak Usia Dini Di Lingkungan Keluarga Dan Sekolah. Jurnal Pratama Widya, 3(2), 41-46.

Wijaya, I. K. W. B. (2019a). ECO FAMILY: METODE PARENTING ANAK USIA DINI UNTUK MEMBENTUK GENERASI LITERASI LINGKUNGAN. Jurnal Pratama Widya, 4, 40-47.

Wijaya, I. K. W. B. (2019b). PEMBELAJARAN SAINS ANAK USIA DINI DENGAN KONSEP TRI PRAMANA. Seminar Nasional Anak Usia Dini, 41-48.

Wijaya, I. K. W. B., Darmayanti, N. W. S., \& Jayadiningrat, I. M. G. (2021). Pembelajaran Sains Anak Usia Dini Dengan Konse p Empat Pilar Pendidikan. Jurnal Pratama Widya, 6(1), 59-65.

Wijaya, I. K. Wi. B. (2018). MENGEMBANGKAN KECERDASAN MAJEMUK SISWA SEKOLAH DASAR (SD) MELALUI PEMBELAJARAN IPA UNTUK MENINGKAT KAN MUTU LULUSAN SEKOLAH DASAR. Jurnal Penjaminan Mutu, 4, 147154

Yusuf. (2019). Pengaruh Pembelajaran Berbasis Masalah Bermuatan Karakter Terhadap Keterampilan Berpikir Tingkat Tinggi dan Karakter Peserta Didik Dengan Mengontrol Kecerdasan Naturalis. Universitas Pendidikan Ganesha. 